\title{
Presenting Cebuano Cinema at the MEMORY! International Film Heritage Festival Paul Douglas Grant
}

Since 2013, the international nongovernmental organization MEMORY! Cinéma Association has held four editions of the MEMORY! International Film Heritage Festival. The first two iterations of the festival took place in Cambodia in June 2013 and June 2014 at Rithy Panh's Bophana Audiovisual Resource Center in Phnom Penh, while the last two took place in Yangon, Myanmar. As the festival's name suggests, MEMORY! is concerned principally with issues of international cinematic heritage and preservation. Duval and Wemaere (2016), the co-general delegates of the festival, in discussing the need for such a heritage festival, noted that "across the world, films are at risk. One half of all films made before 1950 and over 80\% made before 1929 are lost forever. Preserving films and enabling access to this heritage is a cause that may be shared by all countries" (p. 2). Part of enabling access involves a daily programming of talks and presentations on issues of preservation, heritage, and exhibition. And this year, one of the presentations was on the problematic history and preservation of Cebuano cinema.

On the one hand, the MEMORY! Festival is the perfect venue for discussing the issues of preservation at a popular level: those in attendance were largely everyday moviegoers, not academics, archivists, or memory professionals. In this way the festival functions as a kind of exhibition wing of the archival project in general, that is, what is preserved does not remain secluded and secreted away from the public but rather brought out so that 
the cultures most affected by the preserved works can interact with them. On the other hand, for those who know the historical struggle of cinema in Cebu, MEMORY! offers a vision of what a preserved and sometimes restored marginalized cinema can look like, even if it is enviable to witness.

For those outside of the Philippines, the country's national cinema is understood largely in terms of Tagalog and Manila-centric production. The names most recognized by the international moviegoing public are likely to be Lino Brocka, Ishmael Bernal, or more recent art house exports like Brillante Mendoza and Lav Diaz. While the importance of such work cannot be diminished merely because of its position in relation to the dominant cinema of the Philippines, it must be addressed from the outset that there are very specific historical, cultural, economic and linguistic reasons for this cinematic hegemony. Given that the Philippines is an archipelago composed of over 7,000 islands, with eight recognized languages, each of which has its own endlessly mutating regional counterparts and dialects totaling upwards of 175 spoken dialects and languages, one would be hard-pressed to make a case for a national cinema that is not polyglot and poly-regional. And, of course, thankfully, in the last few years there has been a movement to give voice to the cinemas coming from areas outside of Manila. But while many regions are today producing some of the most innovative work in the Philippines, historically, Cebu was the one principal challenger to Tagalog cinema, a challenger that had its own history, its own directors, its own stars, and even a long tradition of local film journalism. In fact in 1951, the National Academy of Motion Picture Arts and Sciences at the Masonic Hall building in Cebu City opened. Cebu offered a powerful retort to Tagalog cinema, particularly in the postwar period up until around 1960, and then again in the 1970s, creating what roughly corresponded to two golden ages of Cebuano cinema. These two ostensible golden ages occurred more or less at the same time that Tagalog cinema was experiencing its own golden ages.

Yet this history of Cebuano cinema has proven to be very difficult to organize into a coherent archival narrative. One of the principal stumbling blocks in researching Cebuano cinema is the rather brute fact that almost the entire body of Cebuano films is as of now missing, and this lack of films calls on precisely a history of non-preservation. For film historians, the concept of a lost film can be intriguing, if not frustrating: an elusive hope of searching for and locating the missing object. What more for those students and historians of an almost-entirely-missing cinema tradition! Those who undertake writing its history will have a difficult time finding anything conventional to say about the films if they cannot be seen. They cannot undertake traditional film analysis like segmentation, thematic 
analyses, sequence, or textual analysis. And in a very rudimentary sense film historians cannot even know whether the films ever existed all, and this is because of the way in which even the mnemic traces of this cinema have been maintained. Perhaps nothing allegorizes the confusion endemic to this history more than the narrative surrounding the alleged first Cebuano film, El Hijo Desobediente, reportedly produced in $1922 .{ }^{1}$ From the very outset the narrative stumbles.

The fourth edition of the MEMORY! Festival pointed out that there are many historical accounts of film movements, directors, time periods, or countries that suffer from a dearth of prints or copies. The very fact that the MEMORY! festival was inaugurated in Cambodia is already testament to this epidemic of missing cinemas. This year, Franco-Cambodian director Davy Chou presented two of his films, his latest project Diamond Island (2016) as well as his first documentary Golden Slumbers (2011). The latter is a project that points to a good example of a lost or missing cinema from Southeast Asia, namely, the pre-1975 films from Cambodia. When the Khmer Rouge seized power, majority of the films from the pre-communist era were destroyed. However, even with such an explicit campaign to eradicate this past-an active attempt to erase a prehistory-a few films survived-films that can be consulted, written about, and preserved. Cebu's history of the so-called "lost cinema" was achieved far less dramatically: quite simply, the films were allowed to fall into desuetude, considered, it would seem, in large part culturally irrelevant.

Myanmar and Cebu also have a degree of shared cinematic history. Myanmar was a British colony at the beginning of the 20th century, and the documentary was an early mainstay of the country's cinema. Like Cebu, its alleged first film was about a funeral: in Myanmar, that of a politician named Tun Shein, while in Cebu, that of the first wife of then-House Speaker Sergio Osmeña Sr, using a newsreel footage by José Nepomuceno. Myanmar eventually turned to narrative filmmaking, the first feature being U Ohn Maung's 1920 Metta Hnint Thuya (Love and Liquor) (Ferguson, 2012, p. 28), and the country enjoyed a productive cinematic culture up until the 1960s. According to Ferguson (2012), one company alone-Parrot Studios-produced 92 films between 1931 and 1957 (p. 29). Over the course of the 20th century and up to the present, cinematic production has largely ebbed and flowed on the back of political shifts in the country. Such political variegations are often the handmaiden of cinematic dropout (again the example of Cambodia being one of the most glaring), but in Myanmar, to a large extent, the political shifts were more noticeable in the body of films being produced and were reflected in the approach to censorship of the films. 
Cebu's ebbs and flows are much more difficult to unpack. While the 1970s under martial law saw a marked uptick in production in Cebu, the period immediately following the Marcos era saw the almost complete disappearance of any film production. In any case it may be unfair to pit and compare a national film history to that of a micro-regional film history. But the principal concern is the difference in approach to archiving and preservation. With the various bodies working in Myanmar, both national and international, perhaps a more democratic approach to preservation and restoration can be implemented in the sense that there is a long history of explicitly politically charged filmmaking in Myanmar-something not shared with Cebu. However, Cebu, as a region that in some sense pitted itself against the dominant vernacular cinema of the Philippines, bore the stamp of a political shibboleth in the name of a kind of regionalism. The product of this antagonism may have some bearing on the current state of preservation of Cebuano cinema as it has created rifts with national film groups. Luckily, however, this is in the process of being repaired.

One critical example today of a Cebuano film, which is conceivably the last existing film from the first so-called golden age of Cebuano cinema, is Eugene Labella's 1954 Kapintas sa Kinabuhi (Cruel Life). Among the principal film directors who emerged from Cebu then and were particularly productive were Natalio "Talyux" Bacalso, Saturnino Villarino, Leox Juezan, Fernando Alfon, and Eugene Labella. Labella was born in Bohol but came to Cebu to study at the University of the Visayas (Visayan Institute). Labella had extensive formal training as the Philippine Government had sent him to Australia from 1957-8 to study film, and then to Tokyo for six months in 1973 (Anissimov \& Grant, 2016, p. 123).

One of Labella's sons, Elmer "Jojo" Labella, reported that he was in possession of two prints of his father's films, Kapintas sa Kinabuhi and Ikaduhang Bathala (1974) (personal communication, October 2014). In the early 2000s, Jojo turned over the prints to the archive of the Cultural Center of the Philippines (CCP). He acknowledged that the print of Ikaduhang Bathala was already beginning to suffer from vinegar syndrome at the time of the handover, but according to him, Kapintas sa Kinabuhi was at that time still in good shape. He was also in possession of a U-matic video copy of Kapintas, but after loaning it to a family member, it disappeared. He also suggested that a U-matic copy had been given to Mowelfund, but that has not been substantiated. According to the CCP archivists, the film prints were successfully deposited; unfortunately, they were not catalogued so that currently, there is no record as to where they are located within the archive (personal communication, October 2014). While it is largely assumed that Ikaduhang Bathala is a lost cause, there is still the possibility of being able 
to preserve and ultimately restore Kapintas sa Kinabuhi. Such a project would provide the Philippines with the oldest known moving image record of cinema in Cebu. And it is here that MEMORY! Film Heritage Festival again comes to the fore as precisely the kind of intervention that Cebu could benefit from.

This year, the fourth edition of the festival championed the theme "transmission." One of the ways the festival integrated the theme was by launching the first edition of the Myanmar Script Fund, a workshop for young Burmese filmmakers to help them develop their first feature film. In this way, the continuation of the project of Burmese cinema is emboldened by MEMORY!, working to ensure that the troubled history of Burmese film preservation and exhibition is curtailed in the future. The other facet of this transmission is of course the exhibition of preserved or recently restored Burmese films, along with other international work. Screened was Tin Maung's 1934 Mya Ga Naing (The Emerald Jungle), the earliest extant Burmese feature film recently restored at l'Immagine Ritrovata. This second aspect is the archival aspect and the mode of transmission of cultural memory to those to whom it should engage as well as those who are lucky enough to come in contact with it.

One would hope that these screenings and restoration projects could one day take root in the regional consciousness of Cebu. But perhaps it is there, in its regional-ness, that we cannot compare the two cinematic histories. Perhaps it is the nature of Burmese cinema that garners the attention of archivists, memory professionals, and above all, the national government, whereas the relics of Cebuano cinema don't appear to offer any real interest to the nation as long as the nation remains bound to a Manila-centric history that is largely narrated in Tagalog and English. But it is not just the nation that remains unmotivated with regards to Cebuano language films of the past; it is equally the Cebuanos themselves. With the restored Burmese films shown at MEMORY! this year and again playing largely to a local popular audience, there was a significant audience at the screening of Ting Maung's 1953 Yatanabon, which had been restored through the collaborative efforts of Myanmar Radio and Television (MRTV) and the Czech National Archive, with very few westerners in attendance. Here we can see the import of such cultural products even to the workaday moviegoer. But screenings of even new Cebuano films in Cebu require an immense amount of footwork in order to have a respectable attendance. One of the assumptions is that the everyday Cebuano has not been given access to a long process of interacting with its own cultural products. This lack-of-access theory is bolstered by the fact that there has never been a regional film archive in $\mathrm{Cebu}$, nor has there been, since the changeover 
to multiplex movie theaters, an alternative exhibition venue consistently offering non-Tagalog or dominant international cinema.

It is this aspect of archiving and preservation in practice and in the service of the public that makes the MEMORY! Film Heritage Festival such an exemplar of cinematic cultural transmission. When Houston (1994) remarked that "access is the watchword ... for the modern film archives" (p. 95), she is emphasizing the utility of an archive. One of the great projects of a successful archive is precisely the type of project that the MEMORY! Cinéma Association has mounted: the festival seeks to make available to the public those archival elements that enrich regional and national heritage and identity. These screenings are what allows an archive its most important office, and here the use of the indefinite article "an" is explicit. To think of an archive in its singular as opposed to a common reference to "the" archive is to strip away the implication that there is some transcendental archive which the public either chooses to use/access or not. The purposeful labor of memory professionals is in some sense pushed to the margins: it is as if there is a permanent depository/repository, unexamined, neutral, and simply waiting to be stocked, and if it goes unused, then that is the fault of the populace-it is the populace who fails to live up to the unilaterally democratic functioning of "the" archive. "An" archive on the other hand, is constructed, can be demolished, is interpreted, and maintained; it can be useful or useless, ultimately assembled and not neutral. And an archive without engagement by both memory workers and the public is a crypt.

Even if all that is left of the Cebuano cinematic heritage from the socalled first golden age, made in the classical mode of production, is a single salvageable film at the CCP archive, that cultural artifact is an example precisely of the kind of transmission that MEMORY! celebrated this year. It is a piece of a missing cinema tradition that challenged linguistic hegemony; that persevered against monolithic distribution difficulties; and that could connect the current generation of filmmakers in Cebu to a history that they should be allowed to know and hopefully champion. In this way, one can hope that something like the heritage militancy of MEMORY! might soon take hold in the Crown Jewel of the South. 


\section{References}

Duval, G., \& Wemaere, S. (2016). MEMORY! International film heritage festival program (4th ed.). Myanmar: MEMORY! Cinéma.

Ferguson, J. (2012). A history of Burmese cinema. In Gimenez, G. M. J.-P. (Ed.). Southeast Asian cinema/Le cinema d'Asie du Sud-Est (pp. 27-37). Lyon: Asiexpo edition

Grant, P., \& Anissimov, M. (2016). Lilas: An illustrated history of the golden ages of Cebuano cinema. Cebu City: USC Press.

Houston, P. (1994). Keepers of the frame: The film archives (1st thus ed.). London: British Film Institute.

PAUL DOUGLAS GRANT teaches graduate cinema studies at the University of San Carlos and currently co-chairs the School of Architecture Fine Arts and Design Research Committee. He is the author of Cinéma Militant: Political Filmmaking and May 1968 and co-author of Lilas: An Illustrated History of the Golden Ages of Cebuano Cinema (corresponding author:pdg244@nyu.edu). 
